\title{
Long-Term Outcome Up To 40 Years after Single Patch Repair of Complete Atrioventricular Septal Defect in Infancy or Childhood
}

\author{
Stefanie Reynen ${ }^{1,2, *}$ Hedwig H. Hövels-Gürich ${ }^{3, *}$ Jaime F. Vazquez-Jimenez ${ }^{1} \quad$ Bruno J. Messmer ${ }^{1}$ \\ Joerg S. Sachweh ${ }^{1}$
}

${ }^{1}$ Department of Surgery for Congenital Heart Disease, RWTH Aachen University, Aachen, Germany

${ }^{2}$ Department of Internal Medicine II (Cardiology), University Hospital Regensburg, Regensburg, Germany

${ }^{3}$ Department of Pediatric Cardiology, RWTH Aachen University,

Aachen, Germany

Thorac Cardiovasc Surg 2021;69:e68-e75.

\begin{abstract}
Address for correspondence Stefanie Reynen, MD, Department of Internal Medicine II (Cardiology), University Hospital Regensburg, Franz-Josef-Strauss-Allee 11, 93053 Regensburg, Germany (e-mail: stefanie.reynen@klinik.uni-regensburg.de).
\end{abstract}

Objectives Patients with repaired complete atrioventricular septal defect (CAVSD) represent an increasing portion of grown-ups with congenital heart disease. For repair of CAVSD, the single-patch technique has been employed first. This technique requires division of the bridging leaflets, thus, among other issues, long-term function of the atrioventricular valves is of particular concern.

Methods Between 1978 and 2001, 100 consecutive patients with isolated CAVSD underwent single-patch repair in our institution. Hospital mortality was $11 \%$. Primary endpoints were clinical status, atrioventricular valve function, and freedom from reoperation in long term. Follow-up was obtained contacting the patient and/or caregiver, and the referring cardiologist.

Results Eighty-three patients were eligible for long-term follow-up (21.0 \pm 8.7 , mean \pm standard deviation $[21.5 ; 2.1-40.0$, median; min-max] years after surgical repair). Actual long-term mortality was $3.4 \%$. Quality of life (QoL; self- or caregiverreported in patients with Down syndrome) was excellent or good in $81 \%$, mild congestive heart failure was present in $16 \%$, moderate in $3.6 \%$ as estimated by New York Heart Association classification. Echocardiography revealed normal systolic left ventricular function in all cases. Regurgitation of the right atrioventricular valve was mild in $48 \%$, mild-moderate in $3.6 \%$, and moderate in $1.2 \%$. The left atrioventricular valve was mildly stenotic in $15 \%$ and mild to moderately stenotic in $2 \%$; regurgitation was mild in $54 \%$, mild to moderate in $13 \%$, and moderate in $15 \%$ of patients. Freedom from left atrioventricular-valve-related reoperation was $95.3,92.7$, and $89.3 \%$ after 5 , 10 , and 30 years, respectively. Permanent pacemaker therapy, as an immediate result

Both authors contributed equally to this work.

received

April 18, 2021

accepted after revision

August 23, 2021
DOI https://doi.org/ $10.1055 / \mathrm{s}-0041-1740070$ ISSN $0171-6425$.

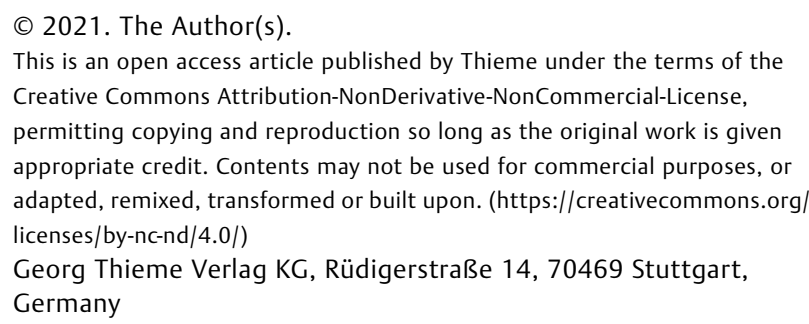


of CAVSD repair ( $n=7)$ or as a result of late-onset sick sinus syndrome $(n=5)$, required up to six reoperations in single patients. Freedom from pacemaker-related reoperation was $91.4,84.4$, and $51.5 \%$ after 5,10 , and 30 years, respectively.

Conclusion Up to 40 years after single-patch repair of CAVSD, clinical status and functional results are promising, particularly, in terms of atrioventricular valve function. Permanent pacemaker therapy results in a life-long need for surgical reinterventions.

\section{Introduction}

Complete atrioventricular septal defects (CAVSDs) account for approximately $2.5 \%$ of congenital heart anomalies. ${ }^{1}$ In patients with Down syndrome, nearly $50 \%$ have an atrioventricular (AV) septal defect, usually the complete variant. ${ }^{2}$ Since the first successful repair of a CAVSD by Lillehei in $1955,{ }^{3}$ three different techniques have been developed to accomplish repair. The single-patch technique was introduced by Maloney in $1962,{ }^{4}$ followed by the two-patch technique by Trusler in $1975,{ }^{5}$ and finally the modified single-patch technique by Wilcox and $\mathrm{Nunn}^{6,7}$ in the late 1990s. Today all techniques are in use at discretion of the surgeon. In contrast to the two-patch and modified singlepatch techniques, the original single-patch technique requires dividing of the bridging leaflets and thus, this technique is of particular interest for the long-term AV valve (AVV) function. Patients with repaired CAVSD resemble a growing population in grown-ups with congenital heart disease (GUCHs). With respect to this, we reviewed our long-term results in patients with CAVSD who had undergone single-patch technique repair up to 40 years ago.

\section{Patients and Methods}

Between 1978 and 2001, 100 consecutive patients with isolated CAVSD underwent single-patch repair at our institution. This technique was fully standardized (B.J.M.) and applied in unison.

\section{Patient Selection}

In this historic series, hospital mortality was $11 \%$. The 89 hospital survivors were subjected to a survey in 2020 using a standardized postal questionnaire or telephone interview with the patients and their cardiologists. If the patient and/or cardiologist was not detectable after decades, the most recent follow-up was considered.

\section{Variables}

\section{Demographic Variables}

- Gender, age at CAVSD repair, and presence of trisomy 21.

Prior to CAVSD Repair

- Placement of a pulmonary artery band (PAB) and pulmonary to systemic resistance (Rp/Rs) prior to CAVSD repair.

\section{At the time of CAVSD Repair}

- Rastelli type of CAVSD, presence of a double orifice "mitral" valve, left-sided papillary muscle anatomy (single, narrow spaced, normally spaced), cleft management (open, partially closed, completely closed), and presence of third degree AV block.

\section{At the Time of Follow Up}

- Death, duration of follow-up, age, QoL (self- or caregiver's estimation), congestive heart failure (New York Heart Association [NYHA] classification), cardiac medication, electrocardiography (rhythm, conduction, tachycardia), 2-day echocardiography (residual shunts, left-ventricular systolic function, AVV's function, subaortic stenosis (SAS), aortic valve function), and CAVSD-related reoperations.

\section{Surgical Technique}

In brief, repair of CAVSD was done via median sternotomy in deep hypothermic circulatory arrest at $20^{\circ} \mathrm{C}$ rectal temperature. If repair could not be completed within approximately 60 minutes, hypothermic low flow bypass was commenced. The right atrium was opened and cold crystalloid cardioplegic solution was administered. After determining the line of apposition, the anterior and posterior bridging leaflets were divided in great favor of the left side leaving only a small rim of tissue for reconstruction of the "septal" part of the rightsided AVV (R-AVV). A Dacron patch was cut to fit into the inlet ventricular septal defect (VSD) far on the right side to prevent from SAS as well as to fit into the primum atrial septal defect (ASD). The patch was sutured to the right part of the crest using continuous 5-0 Prolene. Next, the left-sided AVV (LAVV) components of the bridging leaflets were resuspended to the patch using 6-0 Ethibond mattress sutures without pledgets and were tied on the right side of the patch. The cleft was closed with several interrupted $6-0$ Prolene sutures. The L-AVV was tested with cold normal saline. If necessary, additional commissuroplasty was done. The remainder of the patch was sewn in place to close the primum ASD. Finally, the bridging leaflet components of the R-AVV were resuspended to the patch using 6-0 continuous Prolene. The right atrium was closed and the patient rewarmed and discontinued from bypass and the chest was closed in standard fashion. At that time, intraoperative transesophageal echocardiography was not performed routinely and since 
echocardiography in the late 1970s and early 1980s was not given or is not comparable to today's standards, echo findings were focused on the status quo at follow-up.

\section{Statistical Analysis}

Statistical analysis was done with SPSS version 22 (SPSS Inc., Chicago, Illinois, United States). Missing values were not replaced and were considered as empty cells in all calculations. Central tendency is expressed by mean and median, dispersion by standard deviation and minimum-maximum. Normal distribution was ruled out by the KolmogorovSmirnov test for most parameters. Consequently, differences among groups were assessed using the two-tailed chi-square or Fisher's exact test for binary and categorical variables and the Mann-Whitney U-test for continuous variables. A logistic regression model was applied, if appropriate. For actuarial survival and for freedom from reoperation, KaplanMeier estimates were calculated; in case of more than one reoperation in a single patient, a new case was created for each reoperation. Primary endpoints were QoL and clinical status, AVV function, and freedom from reoperation in long term. A value of $p<0.05$ was considered statistically significant.

\section{Results}

\section{Follow-Up}

Eighty-nine patients were subjected to follow-up. Of these, six patients $(6.7 \%)$ were identified to be survivors, but no additional information could be acquired. These patients were included for survival estimates, but excluded for further analysis. In the remaining 83 patients (study group), age at follow-up was $22.9 \pm 9.3(22 ; 2.5-44.9)$ years; 65 patients (78\%) were older than 15 years, 52 (63\%) older than 20 , and 18 (22\%) older than 30 years; 42 patients (51\%) were male and 65 (78\%) had trisomy 21 . Follow-up after surgical repair was $21.0 \pm 8.7(21.5 ; 2.1-40)$ years (1,744 patient-years). - Fig. 1 summarizes the status quo at the time of follow-up.

\section{Long-Term Survival}

Late mortality ( $n=3)$ was related to pulmonary hypertension, unknown reason, and pacemaker malfunction after trauma 2.1, 8.3, and 8.5 years after CAVSD repair, respectively. Thus, long-term actual mortality was $3.4 \%$ and actuarial long-term survival was $98.8,96.3$, and $96.3 \%$ at 5,10 , and 20 years (number of patients at risk: 78,73 , and 49 , respectively).

\section{Quality of Life and Clinical Status}

\section{Quality of Life}

QoL estimation (self- or caregiver reported in patients with Down syndrome) was obtained from 67/80 patients ( 3 nonsurvivors and 13 nonresponders to the question regarding their QoL were excluded). Considering all 80 eligible patients, 65 (81\%) considered their QoL excellent or good. In two patients, one with Down syndrome, QoL was estimated as impaired. The only pathological finding in these 28 -year-old patients was a moderate L-AVV regurgitation and mild congestive heart failure. There was no statistically significant difference in estimated QoL between patients with or without trisomy $(p=0.247)$.

\section{Clinical Status}

Sixteen patients (19\%) had congestive heart failure, mostly mild: of these, three patients were in NYHA stage III; one

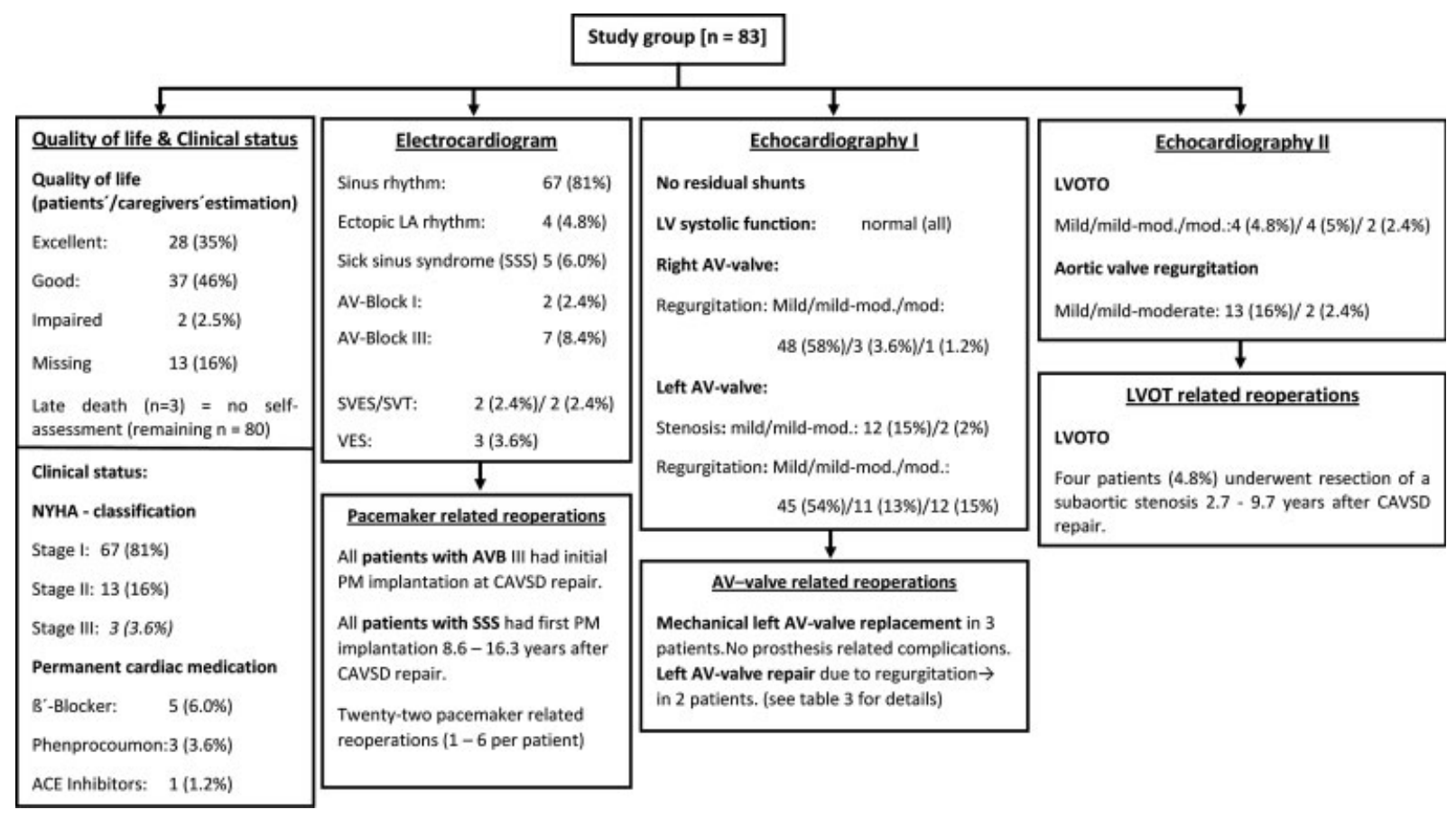

Fig. 1 Status quo at follow-up. ACE, angiotensin converting enzyme; AV, atrioventricular; LA, left atrial; LV, left ventricular; LVOT(O), left ventricular outflow tract (obstruction); NYHA, New York Heart Association; SVES, supraventricular extrasystole; SVT, supraventricular tachycardia; VES, ventricular extrasystole. 
died 2.1 years after CAVSD repair and pacemaker implantation. This patient developed SAS, moderate L-AVV regurgitation, and pulmonary hypertension. The other two patients, age 28 and 38, both with trisomy 21, had an unremarkable follow-up, except for mild L-AVV regurgitation.

\section{Rhythm}

Detailed information is displayed in - Fig. 1. A surgical complete AV-block has implications for lifetime. Thus, it accounts for the majority of reoperations. In this series there were no major complications related to pacemaker therapy. A notable finding is the occurrence of a late-onset sick sinus syndrome (SSS) in five patients 8.6 to 16.3 years after CAVSD repair necessitating pacemaker implantation. The occurrence of SSS was not related to any other investigated variable. All patients with a history of supraventricular tachycardia or ventricular extrasystole were treated with $\beta$-blockers resulting in symptom and tachyarrhythmia free regular follow-up.

\section{Echocardiographic Findings}

In terms of surgical technique, the function of the AVVs is of major interest. Functional parameters of the L-AVV were analyzed in relation to pre- and intraoperative findings as well as to follow-up data ( - Table $\mathbf{1}$ ).

\section{Right AV-Valve}

A more than mildly incompetent R-AVV was found only in four patients (4.8\%), thus analytic statistics were not performed. All had Rastelli type A. The only patient with a moderate R-AVV regurgitation had additional moderate LAVV regurgitation, mild SAS, mild aortic insufficiency, and history of PAB. Regurgitation did not allow for right-ventricular systolic pressure estimation in the majority of patients, thus, a correlation between regurgitation and pressure could not be evaluated.

\section{Left AV-Valve}

In contrast to the R-AVV, there were more patients with more than mild regurgitation (28\%), which was not related to the duration of and age at follow-up ( $p=0.114$ and 0.133 , respectively). There were no statistically significant relations of L-AVV regurgitation to any investigated variables; however, a more than mild L-AVV regurgitation tends to be related to an increased Rp/Rs before CAVSD repair, Rastelli type $B$, and the presence of a pacemaker (-Table 1).

There were 14 patients with L-AVV stenosis, mostly mild $(n=12)$. The stenosis was statistically related to the presence of a double-orifice L-AVV (3/5 (60\%) vs. 10/75 (13\%); $p=0.028$ ). However, L-AVV stenosis was mild in these cases. Double orifice was genuine anatomy not related to an approach to repair an incompetent L-AVV. Stenosis was not related to the Rastelli type of anatomy ( $p=0.721)$, presence of a single- or narrow-spaced papillary muscle $(p=0.610)$, or cleft management $(p=0.405)$. However, not from the statistical point of view, but in practical terms, the anatomy and the surgical technique most likely alter the AVV function (-Fig. 2).
Table 1 Long-term left AV-valve incompetence related to potential risk factors

\begin{tabular}{|c|c|c|}
\hline Variable & $\begin{array}{l}\text { LAVVI > grade } 1 \\
(n=23)\end{array}$ & Prob. \\
\hline $\begin{array}{l}\text { Gender } \\
\text { Male }(n=42) / \text { female }\end{array}$ & $26 \% / 32 \%$ & 0.629 \\
\hline $\begin{array}{l}\text { Trisomy } 21 \\
\text { Yes }(n=65) / \text { no }\end{array}$ & $29 \% / 29 \%$ & 1.0 \\
\hline $\begin{array}{l}\text { Previous PAB } \\
\text { Yes }(n=10) / \text { no }\end{array}$ & $26 \% / 50 \%$ & 0.141 \\
\hline $\begin{array}{l}\text { Rp/Rs }>0.20 \\
\text { Yes }(n=39) / \text { no }\end{array}$ & $16 \% / 37 \%$ & 0.092 \\
\hline $\begin{array}{l}\text { Rastelli type } \\
\mathrm{A}(n=63) / \mathrm{B}(2) / \mathrm{C}(18)\end{array}$ & $29 \% / 100 \% / 19 \%$ & 0.057 \\
\hline $\begin{array}{l}\text { Papillary muscle } \\
\text { Normally spaced }(n=72) / \\
\text { narrow }(2) / \text { single }(5)\end{array}$ & $29 \% / 0 \% / 40 \%$ & 0.466 \\
\hline $\begin{array}{l}\text { Double orifice } \\
\text { Yes }(n=5) / \text { no }\end{array}$ & $31 \% / 0 \%$ & 0.314 \\
\hline $\begin{array}{l}\text { Cleft LAVV } \\
\text { Open }(n=6) / \text { partially closed } \\
(27) / \text { closed }(47)\end{array}$ & $17 \% / 26 \% / 32 \%$ & 0.683 \\
\hline $\begin{array}{l}\text { NYHA } \\
\text { Stage I }(n=67) / \text { II (13)/III (3) }\end{array}$ & $25 \% / 50 \% / 33 \%$ & 0.200 \\
\hline $\begin{array}{l}\text { Pacemaker } \\
\text { Yes }(n=12) / \text { no }\end{array}$ & $55 \% / 25 \%$ & 0.069 \\
\hline $\begin{array}{l}\text { LAVVS (any) } \\
\text { Yes }(n=13) / \text { no }\end{array}$ & $31 \% / 28 \%$ & 1.0 \\
\hline $\begin{array}{l}\text { LVOTO (any) } \\
\text { Yes }(n=10) / \text { no }\end{array}$ & $40 \% / 27 \%$ & 0.462 \\
\hline $\begin{array}{l}\text { Aortic valve reg. } \\
\text { Yes }(n=15) / \text { no }\end{array}$ & $47 \% / 25 \%$ & 0.116 \\
\hline
\end{tabular}

Abbreviation: AV, atrioventricular; LAVV, left atrioventricular valve; LVOTO, left ventricular outflow tract (obstruction); NYHA, New York Heart Association; $\mathrm{PAB}$, pulmonary artery band; $\mathrm{Rp} / \mathrm{Rs}$, pulmonary to systemic resistance. Note: Statistical tendency toward significance $(p<0.10)$ is highlighted in bold and cursive.

\section{Reoperations}

Thirty-four reoperations deemed necessary in 21 patients (25\%) (-Fig. 3). Among those, surgical complete AV-block and late SSS were the most common etiologies for reoperations and for multiple surgical interventions in single patients. Reoperations for L-AVV pathology was the second most common, necessitating up to three reoperations in a single patient (-Table 2). Reoperation for SAS deemed necessary in four patients in whom there is no residuum 21 to 30 years after SAS repair.

\section{Discussion}

Since its introduction in the early $1960 s,{ }^{4}$ the single-patch technique has become an established technique for repair of CAVSDs. However, this technique requires division of the bridging leaflets, and thus is of concern, particularly in the long term. We applied this technique solely and unmodified from 1978 until 2001 resulting today in a large group of 


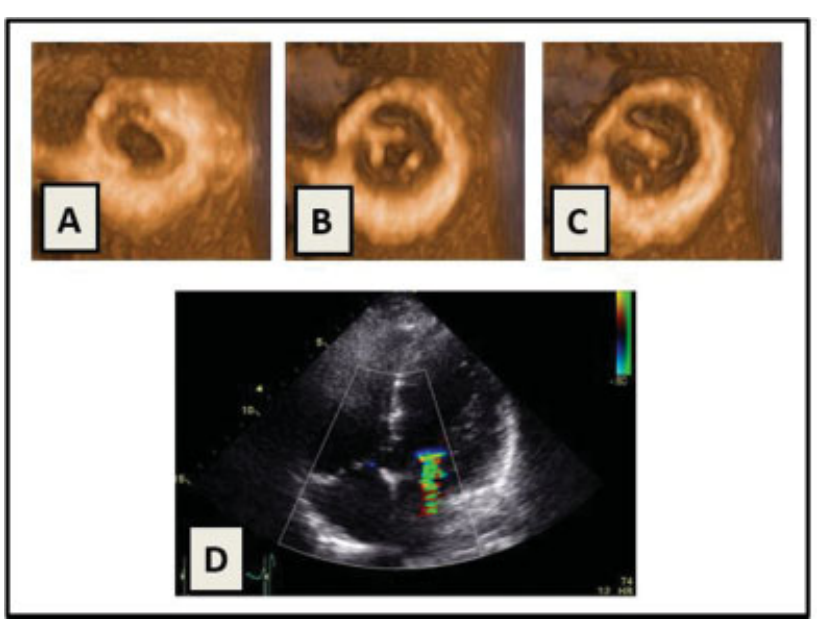

Fig. 2 21-year-old CAVSD repair (with partial closure of the cleft). 3D echocardiography patient post (view from left ventricle) showing full opening of the left-sided AV-valve (A), the partial closure of the left $(B)$, and the thickness cleft line in ventricular systole (C). Restriction of the anterior leaflet of the reconstructed left-sided $A V$ valve and partial closure of the cleft led to mild to moderate insufficiency; 2D echocardiography seen from four-chamber view (D). CAVSD, complete atrioventricular septal defect.

GUCH patients repaired uniformly and providing a long follow-up.

Long-term actual mortality was 3.4\% and actuarial longterm survival was $98.8,96.3$, and $96.3 \%$ at 5,10 , and 20 years, which is in line with other large and recent series. ${ }^{8-10}$ Reasons for death were unknown in one and disease-related in two cases.

\section{Quality of Life and Clinical Presentation}

Up to 40 years after CAVSD repair, in the majority of patients a self- or proxy-reported (caregivers of patients with Down syndrome) excellent or good QoL was estimated, with no difference for patients with trisomy 21 . The possible impact of procedural-related factors (e.g., deep hypothermic circulatory arrest) on long-term (e.g., neurologic) outcome is a matter of concern. However, a differentiated statement based on our data is not possible. Application of established standardized tests to evaluate health-related QoL or objective exercise capacity in patients with Down syndrome is not possible. This may reflect the sparse information on these issues in the literature as well. However, Graves et al have reported on self-reported QoL assessment in a group of adults with Down syndrome, irrespective of the diagnosis of a cardiac defect: they had average scores about one negative standard deviation below normative samples for healthy persons. Especially their physical role scores were reduced due to the impact of diverse health problems on typical accomplishments. ${ }^{11}$

Following the NYHA classification of congestive heart failure, no or only mild limitation of the subjective physical exercise capacity was estimated for $96 \%$ of the patients. This is underlined by the excellent clinical status and the very limited need for cardiac medication which is mainly administered for anticoagulation in patients with mechanical heart valve prostheses and for atrial or ventricular arrhythmias. Systolic left ventricular function was within the normal range, additionally supporting the estimation in terms of good physical exercise capability and low prevalence of congestive heart failure.

\section{Atrioventricular Valve Function}

The repaired AVVs, particularly the left one, have always been a matter of concern, particularly after single-patch repair. In our series, a more than mild R-AVV regurgitation was only found in $5 \%$ of patients and has not been an indication for reoperation so far. There was no stenosis, although at CAVSD repair, tissue of the common AVV, has been separated generously in favor toward the "left side." The L-AVV is hemodynamically the most loaded valve of the heart. In CAVSD, this valve is, in addition, structurally different from a normal mitral valve; furthermore, it is subject to subtle surgical repair. Malfunction eventually will have impact on exercise capability, QoL, and life expectancy. ${ }^{12,13}$

Nevertheless, a moderate regurgitation was found in only $15 \%$ of patients with no indication for reoperation up to the time of the study. There was a trend $(0.1>p>0.05)$ toward more than mild regurgitation for patients with higher pulmonary artery resistance prior CAVSD repair, Rastelli type B,

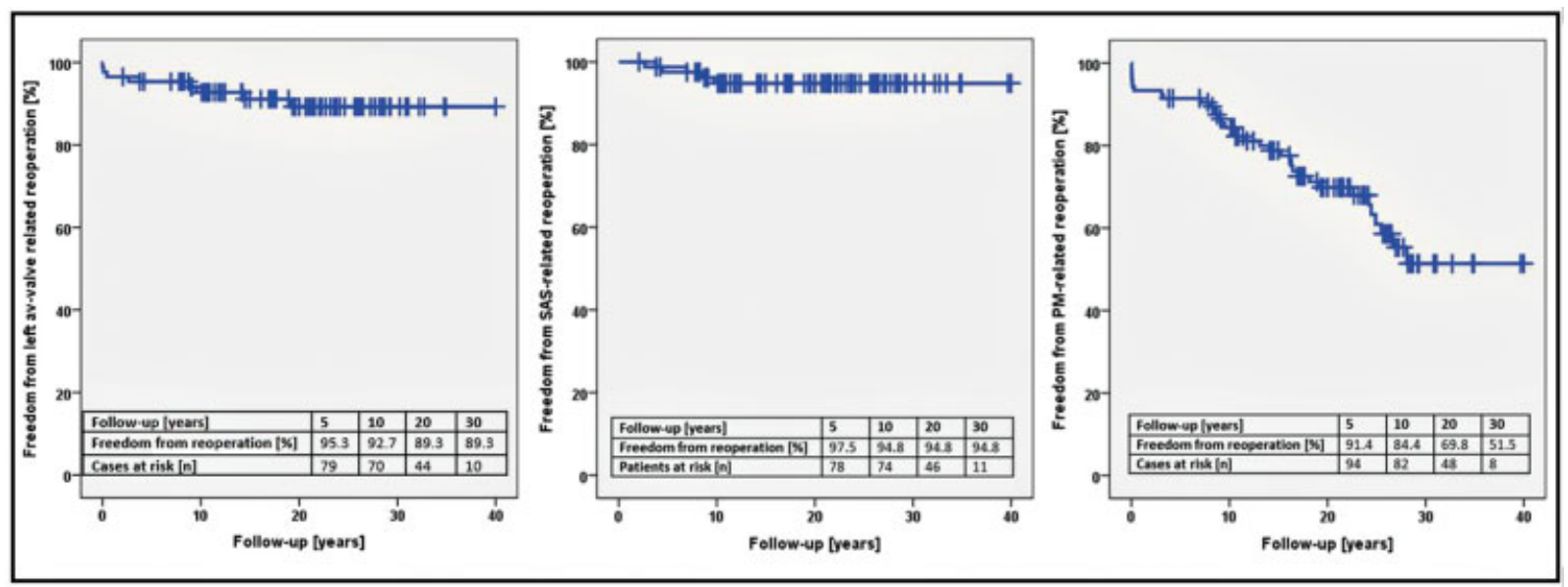

Fig. 3 Freedom from CAVSD repair related reoperations. 


\begin{tabular}{|c|c|c|c|c|c|}
\hline 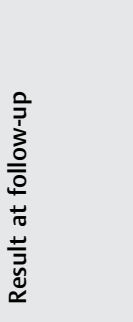 & 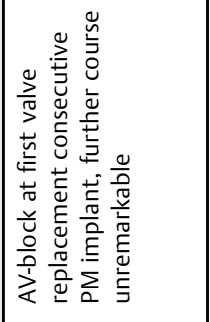 & 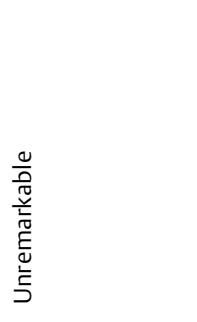 & 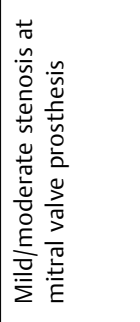 & 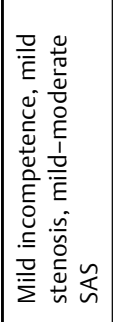 & 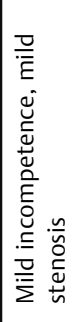 \\
\hline 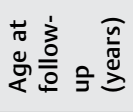 & $\stackrel{\stackrel{n}{m}}{ }$ & $\stackrel{\infty}{\sim}$ & $\bar{\gamma}$ & $\stackrel{\infty}{\sim}$ & $\approx$ \\
\hline 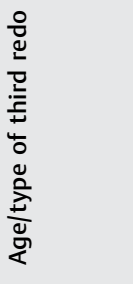 & $\begin{array}{l}\tilde{\nu} \\
\text { ¿े } \\
z\end{array}$ & 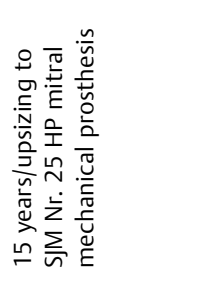 & 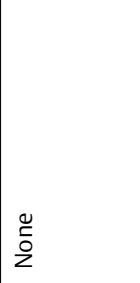 & 䓂 & 蒿 \\
\hline 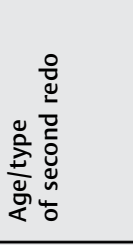 & 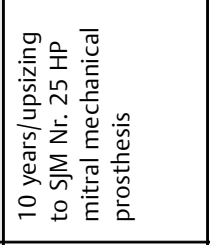 & 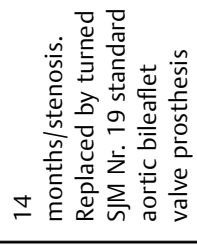 & 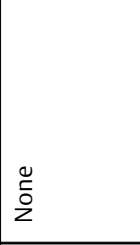 & $\begin{array}{l}0 \\
\stackrel{0}{z} \\
\end{array}$ & $\begin{array}{l}0 \\
\stackrel{0}{z} \\
\end{array}$ \\
\hline 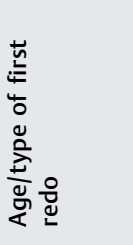 & 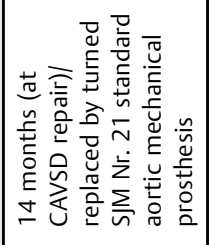 & 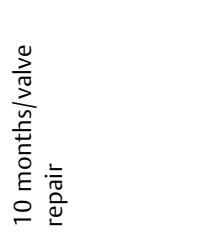 & 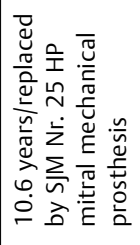 & 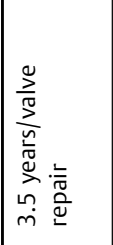 & 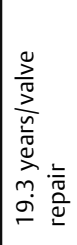 \\
\hline 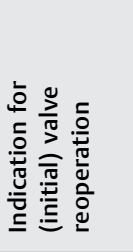 & 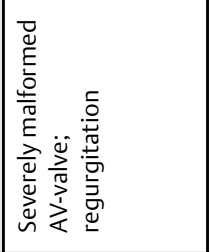 & 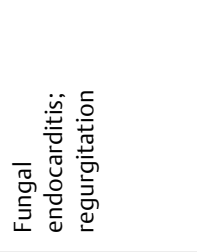 & 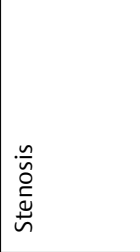 & 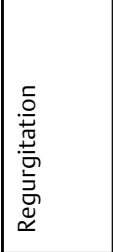 & 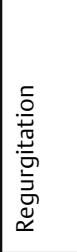 \\
\hline 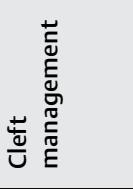 & \begin{tabular}{|l}
$\bar{\emptyset}$ \\
Oิ
\end{tabular} & $\begin{array}{l}\stackrel{\Xi}{u} \\
\stackrel{\varrho}{U}\end{array}$ & 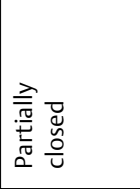 & 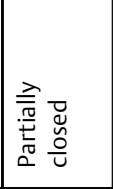 & \begin{tabular}{|l}
$\bar{\Xi}$ \\
Oิ
\end{tabular} \\
\hline 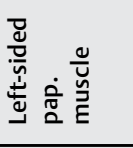 & \begin{tabular}{|l}
$\frac{0}{\bar{\sigma}}$ \\
$\bar{\Sigma}$
\end{tabular} & $\begin{array}{l}\bar{\pi} \\
\tilde{E} \\
\dot{0} \\
z\end{array}$ & $\begin{array}{l}\frac{\pi}{\pi} \\
\vdots \\
\overline{5}\end{array}$ & \begin{tabular}{|l}
$\bar{\pi}$ \\
$\tilde{E}$ \\
$\overline{2}$ \\
\end{tabular} & \begin{tabular}{|l}
$\overline{\widetilde{N}}$ \\
$\tilde{E}$ \\
2 \\
\end{tabular} \\
\hline ¿̀ & 2 & $\stackrel{0}{z}$ & z & 2 & $\stackrel{\tilde{u}}{\succ}$ \\
\hline 岀 & $\varangle$ & $\cup$ & $\cup$ & $\cup$ & $<$ \\
\hline 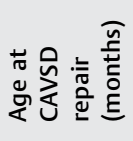 & $\underset{\square}{ \pm}$ & $a$ & $m$ & $=$ & $\sim$ \\
\hline$\underset{\sim}{\stackrel{N}{r}}$ & 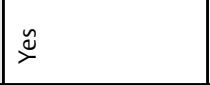 & 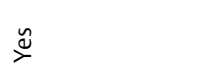 & i & $\stackrel{\check{\varpi}}{\rightleftharpoons}$ & 2o \\
\hline & \# & \# & $\begin{array}{l}m \\
\# \\
\end{array}$ & $\begin{array}{l}* \\
\# \\
\end{array}$ & $\begin{array}{l}\text { in } \\
\# \\
\end{array}$ \\
\hline
\end{tabular}


and the presence of a pacemaker. So far, there are no longterm data available confirming these observations. However, from a pathoanatomical standpoint, these findings may be related to the severity of regurgitation. In contrast, we found that a moderate regurgitation of the L-AVV was not related to the presence of trisomy 21, history of pulmonary artery banding, cleft management, and duration of or age at followup. Particularly, pulmonary artery banding has been of concern altering AVV function. In our series, 10 patients had prior pulmonary artery banding; however, it was not related to L-AVV regurgitation in the long term. In contrast to our finding, Buratto and colleagues report freedom from LAVV reoperation of $60 \%$ after 20 years in a series of 40 patients with prior pulmonary artery banding. ${ }^{14}$

Given a normal systolic left ventricular function and no residual shunts in all patients in our series, evaluation and comparison of bilateral AV function should be reliable. Both AVVs were statistically evaluated taking preoperative, operative, and postoperative variables and follow-up time into account. In general, stenosis was not found on the R-AVV, where it was found to a mild to moderate extent in $2 \%$ in the L-AVV. More than mild regurgitation was more common on the "mitral" side as well ( 28 vs. $5 \%$ ). This result is probably related to the higher pressure load on the systemic side and reflects why reoperations on the "tricuspid" side are rare after CAVSD repair.

\section{Reoperations}

\section{Atrioventricular-Valve-Related Reoperations}

In general, L-AVV regurgitation represents the most common indication for reoperation in 7 to $20 \%$ of patients. ${ }^{8,15-18}$ Freedom from reoperation for L-AVV malfunction has been reported as low as $62 \%$ after 10 years. ${ }^{16}$

In our series, reoperation for L-AVV pathology deemed necessary in five patients (6\%), which is comparable with other series of single-patch repair. ${ }^{19}$ Taking into account the reoperations for valve upsizing, actuarial freedom from "mitral" reoperation was $93 \%$ after 10 and $89 \%$ after 20 years, this again nicely fits to the experience of other groups. ${ }^{19}$ Comparing these results with those of the Australian CAVSD study group ${ }^{10}$ having included more than 800 patients with two-patch or modified single-patch repair, freedom from LAVV index (L-AVVI)-related reoperation at 10 and 20 years was 82.7 and $77 \%$, respectively. In addition, Fong and colleagues found that patients without Down syndrome and moderate L-AVV regurgitation on postoperative echocardiogram were found to be independent risk factors for reoperation in the Australian series. We did not find a relation between the presence of trisomy and L-AVV malfunction. There was no obvious reason for these very promising results, nevertheless, as surgical results are undoubtedly related to small technical details, comparing the "same" technique among different surgical teams does not mean that they are necessarily fully comparable.

Backer and colleagues performed a meta-analysis of the three repair techniques and found that the rate of reoperation for L-AVV regurgitation was $2 \%$ in the modified singlepatch versus $7 \%$ in the two-patch group and $9.7 \%$ in the classic single-patch group, respectively. ${ }^{20}$ In a large recent series, Schleiger and colleagues report on an indication for reoperation for L-AVVI after repair of different anatomical variants of AVSD of $13.8 \%{ }^{21}$ Other series of CAVSD repair using the two-patch technique proved a 10 -year freedom from LAVV reoperation of $94 \%{ }^{15}$

However, we did not provide a comparative study of different repair techniques; nevertheless, we report on a considerable number of GUCH patients in whom the need for reoperation for AVV malfunction was low.

In case of irreparable L-AVV, as we have experienced in three patients, mechanical valves are the usual option in pediatric patients. $^{22}$ If implanted early in life, there is a need for upsizing the prosthesis due to outgrowth which may be achieved with low morbidity and mortality. ${ }^{22,23}$ Even after three decades on mechanical valves in mitral position, there was an unremarkable history in terms of thromboembolism or bleeding events in all, underlining the experience in the literature. ${ }^{2-24}$ It is probably noteworthy that long-term self-management of anticoagulation may play an important role in this setting. ${ }^{24}$

\section{Pacemaker-Related Reoperations}

In contrast to the majority of series, L-AVV pathology was not the most common indication for reoperation. We found that pacemaker-elated reoperations were more common and that the number of patients with immediate damage to the conduction system during CAVSD repair was increased by a considerable number of patients with SSS in the long term. This is a known finding and varies between 2.3 and $12 \%{ }^{16,25}$ In our series, the incidence of SSS-related pacemaker implantation was $6 \%$. However, as we have observed that SSS may develop up to 16 years post-CAVSD repair, life-long observation deemed necessary. Taking both etiologies into account, there is a low freedom from pacemaker-related freedom from reoperations, i.e., 70\% after 20 and only 52\% after 30 years. Although, there were no major issues related to pacemaker therapy in general, one of our long-term deaths was most likely related to pacemaker malfunction.

\section{Left Ventricular Outflow Tract Obstruction}

SAS is a well-known mid- to long-term complication after CAVSD repair. ${ }^{26-28}$ In a large series from Mayo Clinic, Stulak et al report that SAS was responsible for approximately $10 \%$ of all patients requiring reoperations. ${ }^{29}$ In our series, $4.8 \%$ of all patients required SAS resection, which is in line with other series of single-patch repair. ${ }^{19}$ Ginde et al report on a freedom from reoperation of $97 \%$ after 10 and $94 \%$ after 20 years, however, with necessity of a re-reoperation in about one-third of these patients. ${ }^{8}$ We observed a comparable freedom from reoperation, with no need for re-repair after up to 30 years. However, the complexity of the SAS will most likely influence the recurrence of the obstruction.

\section{Conclusion}

Up to 40 years after single-patch repair for CAVSD in infancy or childhood, the functional outcome is excellent and the need for L-AVV reoperation is very promising. Pacemaker- 
related reoperations are common and related to surgical and late-onset etiology as well.

\section{Limitations}

This study is limited by its retrospective character and, due to the long timeframe, by the inability to obtain a recent clinical follow-up examination from every patient. In addition, the study is based on the clinical estimation, electrocardiographic and in particular echocardiographic interpretation of many further care cardiologists, rather than obtaining findings exclusively by the authors of the present study. Nevertheless, this study is not aiming at meticulous analysis, which is, based on the methodology, not possible, but it provides much useful information of long-term results of a surgical technique applied uniformly in a large cohort.

\section{Funding}

This research received no specific grant from any funding agency, commercial, or not-for-profit sectors.

\section{Conflicts of Interest}

None.

\section{Acknowledgments}

The first and second authors contributed equally and were of prime importance to the idea, concept, data acquisition, and analysis as well as to the discussion of this work.

\section{References}

1 Lindinger A, Schwedler G, Hense HW. Prevalence of congenital heart defects in newborns in Germany: results of the first registration year of the PAN Study (July 2006 to June 2007). Klin Padiatr 2010;222(05):321-326

2 Freeman SB, Taft LF, Dooley KJ, et al. Population-based study of congenital heart defects in Down syndrome. Am J Med Genet 1998;80(03):213-217

3 Lillehei CW, Cohen M, Warden HE, Varco RL. The direct-vision intracardiac correction of congenital anomalies by controlled cross circulation; results in thirty-two patients with ventricular septal defects, tetralogy of Fallot, and atrioventricularis communis defects. Surgery 1955;38(01):11-29

4 Maloney JV Jr, Marable SA, Mulder DG. The surgical treatment of common atrioventricular canal.J Thorac Cardiovasc Surg 1962;43:84-96

5 Trusler GA. Discussion of Mills NL, Ochsner JL, King TD. Correction of type C complete atrioventricular canal. Surgical considerations. J Thorac Cardiovasc Surg 1976;71:20-28

6 Wilcox BR, Jones DR, Frantz EG, et al. Anatomically sound, simplified approach to repair of "complete" atrioventricular septal defect. Ann Thorac Surg 1997;64(02):487-493, discussion 493-494

7 Nicholson IA, Nunn GR, Sholler GF, et al. Simplified single patch technique for the repair of atrioventricular septal defect. J Thorac Cardiovasc Surg 1999;118(04):642-646

8 Ginde S, Lam J, Hill GD, et al. Long-term outcomes after surgical repair of complete atrioventricular septal defect. J Thorac Cardiovasc Surg 2015;150(02):369-374

9 Crawford FA Jr, Stroud MR. Surgical repair of complete atrioventricular septal defect. Ann Thorac Surg 2001;72(05):1621-1628, discussion 1628-1629

10 Fong LS, Betts K, Ayer J, et al; Australian CAVSD study group. Predictors of reoperation and mortality after complete atrioven- tricular septal defect repair. Eur J Cardiothorac Surg 2021; May 18: ezab221. doi: 10.1093/ejcts/ezab221. PMID: 34002204

11 Graves RJ, Graff JC, Esbensen AJ, Hathaway DK, Wan JY, Wicks MN. Measuring health-related quality of life of adults with Down syndrome. Am J Intellect Dev Disabil 2016;121(04):312-326

12 McGrath LB, Gonzalez-Lavin L. Actuarial survival, freedom from reoperation, and other events after repair of atrioventricular septal defects. J Thorac Cardiovasc Surg 1987;94(04):582-590

13 Günther T, Mazzitelli D, Haehnel CJ, Holper K, Sebening F, Meisner H. Long-term results after repair of complete atrioventricular septal defects: analysis of risk factors. Ann Thorac Surg 1998;65 (03):754-759, discussion 759-760

14 Buratto E, Khoo B, Ye XT, et al. Long-term outcome after pulmonary artery banding in children with atrioventricular septal defects. Ann Thorac Surg 2018;106(01):138-144

15 Bakhtiary F, Takacs J, Cho MY, et al. Long-term results after repair of complete atrioventricular septal defect with two-patch technique. Ann Thorac Surg 2010;89(04):1239-1243

16 Houck CA, Evertz R, Teuwen CP, et al. Dysrhythmias in patients with a complete atrioventricular septal defect: from surgery to early adulthood. Congenit Heart Dis 2019;14(02):280-287

17 Sojak V, Kooij M, Yazdanbakhsh A, Koolbergen DR, Bruggemans EF, Hazekamp MG. A single-centre 37-year experience with reoperation after primary repair of atrioventricular septal defect. Eur J Cardiothorac Surg 2016;49(02):538-544, discussion 544-545

18 Ten Harkel AD, Cromme-Dijkhuis AH, Heinerman BCC, Hop WC, Bogers AJ. Development of left atrioventricular valve regurgitation after correction of atrioventricular septal defect. Ann Thorac Surg 2005;79(02):607-612

19 Dragulescu A, Fouilloux V, Ghez O, Fraisse A, Kreitmann B, Metras D. Complete atrioventricular canal repair under 1 year: Rastelli one-patch procedure yields excellent long-term results. Ann Thorac Surg 2008;86(05):1599-1604, discussion 1604-1606

20 Backer CL, Kaushal S, Mavroudis C. Modified single-patch technique: repairing complete atrioventricular septal defect. Ann Pediatr Cardiol 2009;2(01):51-54

21 Schleiger A, Miera O, Peters B, et al. Long-term results after surgical repair of atrioventricular septal defect. Interact Cardiovasc Thorac Surg 2019;28(05):789-796

22 Sachweh JS, Tiete AR, Mühler EG, et al. Mechanical aortic and mitral valve replacement in infants and children. Thorac Cardiovasc Surg 2007;55(03):156-162

23 Ackermann K, Balling G, Eicken A, Günther T, Schreiber C, Hess J. Replacement of the systemic atrioventricular valve with a mechanical prosthesis in children aged less than 6 years: late clinical results of survival and subsequent replacement. J Thorac Cardiovasc Surg 2007;134(03):750-756

24 Mair H, Sachweh J, Sodian R, et al. Long-term self-management of anticoagulation therapy after mechanical heart valve replacement in outside trial conditions. Interact Cardiovasc Thorac Surg 2012;14(03):253-257

25 Di Mambro C, Calvieri C, Silvetti MS, et al. Bradyarrhythmias in repaired atrioventricular septal defects: single-center experience based on 34 years of follow-up of 522 patients. Pediatr Cardiol 2018;39(08):1590-1597

26 Backer CL, Eltayeb O, Mongé MC, et al. Modified single patch: are we still worried about subaortic stenosis? Ann Thorac Surg 2015; 99(05):1671-1675, discussion 1675-1676

27 Overman DM. Reoperation for left ventricular outflow tract obstruction after repair of atrioventricular septal. Semin Thorac Cardiovasc Surg Pediatr Card Surg Annu 2014;17(01):43-47

28 Valeske K, Huber C, Mueller M, et al. The dilemma of subaortic stenosis-a single center experience of 15 years with a review of the literature. Thorac Cardiovasc Surg 2011;59(05):293-297

29 Stulak JM, Burkhart HM, Dearani JA, et al. Reoperations after initial repair of complete atrioventricular septal defect. Ann Thorac Surg 2009;87(06):1872-1877, discussion 1877-1878 